\title{
Outcome Of Immediate PPIUCD At Follow Up Visit In Women At A Tertiary Care Hospital In Karachi, Pakistan
}

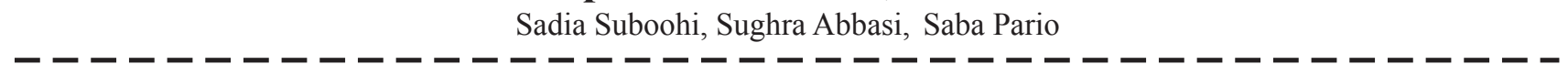

ABSTRACT:

Objective: To evaluate the outcome of Immediate Post Partum Intrauterine Contraceptive device (PPIUCD) insertion among married women of reproductive age at a tertiary care Creek General Hospital, Karachi, Pakistan.

Study Design: Prospective Interventional study.

Methodology: The clinical study was conducted in department of Obstetrics \& Gynaecology, Creek General hospital Karachi from August 2015 to July 2016. One hundred and twenty five women were selected for immediate PPIUCD insertion, however the result was analysed for hundred women as twenty five were lost to follow-up. PPIUCD was inserted within 10 minutes of delivery of placenta. Follow up was done at 6 weeks, the primary outcome measures were the clinical outcomes in terms of safety (irregular vaginal bleeding, abnormal vaginal discharge, infection and perforation) and efficacy (un-descended IUCD strings, expulsion, discontinuation and pregnancy). The results were analyzed by SPSS data analysis software (IOBM).

Results: Among hundred women in whom PPIUCD was inserted and returned for follow-up, majority (44\%) were in age group 26-30 years; around 52\% had primary or less education, and considerably high (84\%) belonged to the low socio economic status. Moreover, majority ( $46 \%$ ) had 3 or more alive children. Importantly, $73 \%$ women had IUCD inserted after vaginal delivery. As safety was evaluated, irregular vaginal bleeding was observed in $15 \%$, abnormal vaginal discharge $(20 \%)$, infection (11\%), abdominal pain (4\%) and perforation in only $1 \%$ of cases. Finally, in terms of efficacy the undescended IUCD strings were observed in 7\%, expulsion incidence (6\%), discontinuation requested by $(5 \%)$ and none of the case ended up in pregnancy.

Conclusion: Post partum IUCD insertion immediately following delivery is an effective, safe, and acceptable long-term reversible method available for postpartum contraception.

Key Words: Complications, contraception, efficacy, Postpartum IUCD, safety

$-------------------------------------$

INTRODUCTION:

Pakistan is sixth most populous country in the world according to Pakistan economic survey 2014- 2015', and the population of the country is growing with an excessive high rate being not matched for the prevalence rate of the contraception use $e^{2}$. Thus, this calls for appropriate measures for promotion and awareness among couples related to the use of contraceptives. Reduction in population growth needs to be one of our top priorities to attain a balance between country's resources and population leading to sustainable feto-maternal health improvement and socioeconomic development. It has been indicated with evidence established that birth spacing can help avoiding almost one third of

Г - - - - - - - - - - - - ר

Sadia Suboohi

Associate Professor, Obstetrics \& Gynaecology
at Creek General Hospital, United Medical \& Dental College, I

I Creek General Hospital, United Medical \& Dental College,

IEmail: drsadiashams@gmail.com

I

Sughra Abbasi

I Associate Professor, Obstetrics \& Gynaecology

I Baqai Medical College \& Hospital

I Saba Pario

Assistant Professor, Obstetrics \& Gynaecology
at Creek General Hospital United Medical \& Dental College, I Karachi

I

Received: $12-10-18$

Accepted: 11-12-18 maternal deaths, if pregnancies were spaced by couple for two or more years ${ }^{3}$. Having short intervals between pregnancies and births have been associated with an increase risk of morbidity as well as mortality, among both mother and child ${ }^{4}$. Irrespective of the fact that numerous contraceptives devices and measures available, certain proportion of women conceive and had unplanned or unwanted pregnancies. Moreover, certain couples have misconception and ignorance about contraception although they desire to use contraceptive measures. Postpartum period is a significant and time of extreme importance when the couples and more importantly mother are highly motivated and have increased level of acceptance to use contraceptive methods. If a contraceptive is provided prior to hospital discharge, then issues related to compliance of woman is minimized and the couple is successfully protected prior resuming the sexual activity ${ }^{5}$. Preventing unwanted or unintended pregnancies are significant in terms of reducing the financial, psychological, and the healthcare costs. The World Health Organisation (WHO) has recommended 24 months waiting time after birth and planning or attempting next pregnancy will decrease the risk of both maternal as well as infant poor health outcomes ${ }^{6}$. Intrauterine Contraceptive device (IUCD) has been associated with improved efficacy, safety with limited complications reported; thus a reliable and safe method for contraception among 
women $^{7-8}$. It is one of the most prevalent, long lasting, and a reversible method of contraception for women of reproductive age globally ${ }^{9}$. Considering, IUCD being a reversible method, it can be removed safely at women desires with return of fertility immediately ${ }^{10}$.

Postpartum IUCD (PPIUCD) insertion can be done post placental that is within 10 min of placental expulsion, intracesarean at the time of cesarean section or within 48 hours of delivery. After the placental delivery insertion of IUCD is relatively safe, thereby allowing increase IUCD insertion post placental for contraception to meet the need of community and contraception provided prior sexual activity is being resumed ${ }^{11}$. While, if a women wait for 6 weeks for initiating an effective contraceptive method, they are possibilities of accidentally or unintentionally and might not come for contraception ${ }^{12}$. PPIUCD insertion is not only advantageous for women and couples, but the healthcare service providers also benefited as ruling out pregnancies definitely, and precious time being saved as the insertion is being performed on the same delivery table with no additional evaluation or distinct clinical procedure required. Simply a special instrument may be required for PPIUCD insertion ${ }^{5}$. Globally it has been estimated that around 85 million women are using IUCD. Moreover, in Pakistan, especially in rural areas where health resources are scarce, it is acceptable to most couples considering its safety, being long acting though reversible, convenience and cost effectiveness ${ }^{13}$. According to reproductive health and family planning survey, $40 \%$ of Pakistani women use contraceptives and IUCD is used by $3.5 \%$ of women after pills and Injectables. Intrauterine devices have been used for more than three decades as an effective method of reversible contraception ${ }^{14}$. The present research was conducted to evaluate the outcomes of Immediate Post Partum Intrauterine Contraceptive device (PPIUCD) insertion i.e. safety and efficacy among women having delivery vaginally or by cesarean section at a tertiary care Creek General Hospital, Karachi, Pakistan.

\section{METHODOLOGY:}

This prospective interventional study was conducted in the department of Obstetrics \& Gynaecology, Creek General hospital Karachi an affiliated teaching hospital of United Medical and Dental College (UMDC), for a period of one year from August 2015 to July 2016. One hundred and twenty five women were recruited in this clinical study for immediate Post placental IUCD (Multiload 375) insertion after satisfying the eligibility criteria. The inclusion criteria for PPIUCD insertions were women with age 18 to 45 years delivering at the study site either vaginally or by caesarean section, having received counseling for postpartum contraception during antenatal period or in labour room, and given written informed consent for PPIUCD insertion. Moreover, anaemic women (hemoglobin $<10 \mathrm{~g} / \mathrm{dl}$ ), postpartum hemorrhage $(\mathrm{PPH})$, pre-labour membranes rupture $>18$ hours or with obstructed labour, having uterine cavity distorted by fibroid or congenital malformation of uterus, pyrexia during labor and delivery, with active sexually transmitted disease or other lower genital tract infections were excluded. Vaginal PPIUCD insertions were done within 10 minutes of removal of placenta by trained doctors; the IUCD being held by the sponge holder was introduced in the uterine cavity and placed in the uterine cavity (fundus) of women. While in case of caesarean section, IUCD was placed inside the uterus (fundus) through the lower segment incision with incision being closed routinely. All aseptic measures were followed throughout the procedure. At discharge women was given card with details of PPIUCD, showing date of insertion, and was informed when to return for IUCD follow-up. Moreover, the study participants were also advised to visit any time if having foul smelling vaginal discharge, pain in the lower abdomen, fever or chills and any suspicion that the IUCD has fallen out.

Post insertion follow-up was done at 6 weeks, and women visiting were inquired for irregular vaginal bleeding, abnormal vaginal discharge, and expulsion. Abdominal and pelvic examination was performed at follow-up visit. If threads were not visible on per speculum examination, an ultrasound was performed to check for expulsion or confirm presence of intrauterine IUCD. In cases where women requested for the removal of IUCD due to any medical or personal reason, counselling was done and if non compliant or refuse, intrauterine device was removed and offered alternative contraceptive method. At recruitment patient's characteristics (i.e. age, education, occupation, socio economic status, ethnicity, number of children alive and future pregnancy desire) were recorded. Moreover, data on reasons for acceptance and insertion (vaginal or caesarean section) was also collected. The primary outcome measures were the clinical outcomes in terms of safety (menstrual irregularities, abnormal vaginal discharge, infection and perforation) and efficacy (Un-descended IUCD strings, expulsion, discontinuation and pregnancy). The clinical study was conducted according to ethical guidelines of Pakistan Medical and Research Council (PMRC) and Helenski declaration. The study is approved by the Ethical review Committee of Creek General hospital Karachi. Written informed consent was obtained from all the participants prior to enrollment. The participants had the right to withdraw at any point of the research. Importantly, it was ensured that anonymity and confidentiality of the study participant data was maintained throughout the research. The data was analysed using SPSS version 22 (IOBM). The data recorded on the pre-designed performa was entered in the SPSS software and validated twice for incorrect entries. Descriptive statistics were performed where categorical variables were presented as frequency/ percentage.

\section{RESULTS:}

A total of one hundred and twenty five women were included in this study. There were twenty five women, being lost to 
follow up. Thus, the response distribution was $80 \%$ and the results were analysed for hundred women being inserted with PPIUCD. The majority of women were in age category $26-30$ years $(44 \%)$, followed by $31-40$ years $(33 \%)$, and 19 25 years $(21 \%)$. Moreover, around fifty two women $(52 \%)$ had no formal education or education up to primary level. Only seventeen women (17\%) had education attained Matric or higher. Importantly, eighty seven percent of women were house wives. As far as ethnicity of the women enrolled in this clinical study was concerned; majority were Urdu speaking (42\%), followed by Pathan (19\%), Sindhi (18\%) and Punjabi (16\%). Moreover, majority (84\%) belonged to the low socio economic status. Among hundred women inserted with PPIUCD, majority (46\%) had three or more children alive, around twenty eight percent had two or more children alive, and twenty six percent had only one child alive. Finally, majority (44\%) had desire of future pregnancy within 3-5 years, thirty one percent had future pregnancy desire within 1-2 years; and considerable proportion were not sure $(16 \%)$ or do not want more $(9 \%)$. The table 1 gives details of the demographic characteristics of the study participants. The table 2 gives details of the PPIUCD insertion and the reasons of acceptance of insertion. Among hundred women PPIUCD was inserted vaginally among seventy three percent women, while remaining twenty three percent had insertion during cesarean section. The most cited reasons for acceptance were doctors advice considering it good (27\%), being safe $(20 \%)$, non-remembrance once inserted $(18 \%)$, being reversible $(15 \%)$ and long-term $(11 \%)$. The reasons non-interference with breast feeding, less number of visits required and being not hormonal were reasons less responded being all less than five percent. The table 3 gives details of safety and efficacy of PPIUCD insertion at followup among study participants. Irregular vaginal bleeding was observed in $15 \%$ of women, $20 \%$ of the women complained of abnormal discharge through vagina and $11 \%$ had signs of infection on examination. Perforation was only observed among one case on follow-up. Moreover, four women (4\%), complaint of abdominal pain and five cases $(5 \%)$ had long strings. The un-descended IUCD strings were reported identified in three cases (3\%). Spontaneous expulsion of IUCD occurred in $6 \%$ cases at follow-up. IUCD removal was done on request of the women.

\section{DISCUSSION:}

Post-partum period is a highly vulnerable period to unintended pregnancy and potentially an important time to start contraception as women are considerable more motivated to accept contraception, thus PPIUCD insertion following delivery of placenta as requiring no extra procedure is more convenient for women and healthcare providers with no extra cost involved. ${ }^{9}$ Intrauterine contraceptive devices (IUCD) has several advantages of its use during post-partum period as being effective, long term, reversible, coitus dependent and non interference with breast feeding. ${ }^{15}$

\begin{tabular}{|l|c|}
\hline Characteristics & n (\%) \\
\hline Age categories (Years) & \\
\hline $19-25$ years & $21(21)$ \\
\hline $26-30$ years & $44(44)$ \\
\hline $31-40$ years & $33(33)$ \\
\hline = 40 years & $2(2)$ \\
\hline Education & $27(27)$ \\
\hline No formal education & $25(25)$ \\
\hline Primary & $31(31)$ \\
\hline Secondary & $17(17)$ \\
\hline Matric and higher & \\
\hline Occupation & $87(87)$ \\
\hline House wife & $13(13)$ \\
\hline Employed & \\
\hline Ethnicity & $18(18)$ \\
\hline Sindhi & $16(16)$ \\
\hline Punjabi & $42(42)$ \\
\hline Urdu Speaking & $19(19)$ \\
\hline Pathan & $5(5)$ \\
\hline Balochi & $84(84)$ \\
\hline Socioeconomic status & $16(16)$ \\
\hline Low & $26(26)$ \\
\hline Middle & $46(28)$ \\
\hline Number of children alive & $31(31)$ \\
\hline One children & \\
\hline Two children & $(44)$ \\
\hline 3 or more children & \\
\hline Future Pregnancy desire & \\
\hline $1-2$ years & \\
\hline $3-5$ years & \\
\hline Not Sure & \\
\hline No More & \\
\hline
\end{tabular}

Table 1: Characteristics of the study participants $(\mathrm{N}=100)$

\begin{tabular}{|c|c|}
\hline PPIUCD insertion and reasons for acceptance & n (\%) \\
\hline PPIUCD insertion & \\
\hline Vaginally & $73(73)$ \\
\hline Cesarean section & $27(27)$ \\
\hline Reasons for acceptance & \\
\hline Safe & $20(20)$ \\
\hline Long term & $11(11)$ \\
\hline Less number of visits required & $2(2)$ \\
\hline Not hormonal & $3(3)$ \\
\hline Non-remembrance once inserted & $18(18)$ \\
\hline Doctor's advice must be good & $27(27)$ \\
\hline Non-interference with breast feeding & $4(4)$ \\
\hline Reversible & $15(15)$ \\
\hline
\end{tabular}

Table 2: Post Partum Intrauterine Contraceptive device (PPIUCD) insertion and reasons for acceptance by the study participants (N $=100$ ) 


\begin{tabular}{|l|c|}
\hline Safety and Efficacy of PPIUCD insertion & $\mathbf{n ~ ( \% )}$ \\
\hline Complications during follow-up visit & \\
\hline Irregular vaginal bleeding & $15(15)$ \\
\hline Abnormal vaginal discharge & $20(20)$ \\
\hline Infection & $11(11)$ \\
\hline Perforation & $1(1)$ \\
\hline Abdominal Pain & $4(4)$ \\
\hline Long strings & $5(5)$ \\
\hline Efficacy & \\
\hline Un-descended IUCD string & $3(7)$ \\
\hline Expulsion & $6(6)$ \\
\hline Discontinuation & $5(5)$ \\
\hline Pregnancy & $0(0)$ \\
\hline
\end{tabular}

Table 3: Safety and Efficacy of Post Partum Intrauterine Contraceptive device (PPIUCD) insertion among study participants $(\mathrm{N}=100)$

Moreover, IUCDs have rapid onset of action after administration with immediate return to fertility after discontinuation ${ }^{16}$. World Health Organisation has recommended the immediate post-placental insertion of IUCD as a safe and effective method for temporary contraception, thus being incorporated in different postpartum family planning programs ${ }^{17}$. However, studies have reported the acceptance of PPIUCD being low ${ }^{18-19}$. The United Nations Population Information Network (UNPOPIN) had highlighted that insertion timing of IUCD is significant as it influences the to a great extent the risk of expulsion ${ }^{20}$. Thus, ideally the IUCD should be inserted within 10 minutes of placental delivery or until 48 hours of delivery to have improved clinical outcomes ${ }^{21}$. In the current study, the IUCD was inserted immediately (within 10 minutes of delivery of placenta) among women having delivery vaginally or by caesarean section

In the clinical study conducted, irregular vaginal bleeding was observed among $15 \%$ of cases being appropriately managed by counselling and conservative treatment. Other studies have reported around similar proportion of irregular vaginal bleeding with PPIUCD insertion ${ }^{22-23}$. Moreover, the abnormal vaginal discharge was observed among $20 \%$ of study participants, which was later confirmed to be infectious among eleven cases after clinical assessment and microbiological confirmation. This is slightly higher $(0.1 \%)$ in the study conducted among women from Paraguay ${ }^{24}$, and considerably higher around 5\% among women in India 25 . Perforation of uterus is a serious complication of IUCD insertion, and was observed in only one case in the study conducted. A study had highlighted that cases with perforation may not be identified at the time of insertion, and are recognised years after and had serious consequences as infection, pain in the abdomen, intestinal obstruction and adhension. ${ }^{26}$ In the present study the case identified with perforation was due to secondary (perforation after 4 weeks of insertion being caused by gradual erosion through the myometrium), the study participant on follow-up visit complained of lower abdominal pain, which was diagnosed by trans-vaginal scan and x-ray and then managed appropriately by laparotomy.

The present study reported the expulsion rate as $6 \%$, being similar to the study conducted by Reetu Hooda et al., $(2016)^{15}$. However, higher expulsion rates were being reported in other studies ${ }^{14,27}$. The expulsion rate for different IUCD's are different, as Multiload have been used that had lower expulsion rate as reported in the study ${ }^{28}$. However, the benefits of highly effective contraceptive provision immediately after delivery surpass the disadvantage of expulsion; being considerable significant in a developing country like Pakistan with high fertility rate, low contraceptive prevalence and limited access to the healthcare facilities. particularly in country like Pakistan where women have limited access to medical care.

In the current study only $5 \%$ of study participants among those inserted with PPIUCD had lost strings during followup visit, which is in agreement with another study that reported less than $9 \%$ of un-descended IUCD strings were observed $^{23}$. However, another study has reported a significantly high incidence (38\%) of un-descended strings ${ }^{15}$. In the current study the request to remove IUCD was observed among $6 \%$ of study participants, being similar to the study by Kumar et al, conducted in $2014^{25}$. However, another study has reported a significantly higher proportion $(15.7 \%)$ of women not willing to continue IUCD and requested to remove ${ }^{29}$. Importantly, in the current study no case of pregnancy was observed among women with PPIUCD insertion, similar to reported findings of other studies ${ }^{15,22}$.

The current clinical study had certain limitations. Firstly, the study was conducted at only hospital, where majority of patients with low socio economic class and low education visits. Secondly, only hundred women with PPIUCD insertion were followed. Thus, limited sample size and selection of only study site had limited the generalisibility and external validity of the study findings. Importantly, the study participants were followed for only six weeks. Thus, in future a study with recruitment of more number of eligible participants from multiple study sites and follow-up for a longer period (i.e. 12 months or 18 months) would be of importance to better identify the clinical efficacy and safety of PPIUCD insertion.

\section{CONCLUSION:}

The present study identified that PPIUCD was an effective and acceptable contraception with fewer complications. In this clinical study conducted it was concluded that PPIUCD insertion within 10 minutes of delivery of placenta, is safe, efficacious, convenient, and a long-term reversible method of postpartum contraception. The recommendations stemming 
out of the study is that PPIUCD insertion should be routinely offered to all eligible women in an antenatal and postpartum period. Moreover, increased emphasis should be given on training programs to improve provider's skills and to evaluate and manage complications.

\section{REFERENCES:}

1. Pakistan economic survey 2014- 2015. Population, Labor Force and Employment Ministry of Finance, Available at: www.finance.gov.pk/survey/chapters_15/12_Population.pdf

2. National Institute of Population Studies Pakistan (NIPS) and Macro International Incorporated (2013) Pakistan demography and health survey report. Pakistan Demographic and Health Survey 2012-2013. Available at: http://www.nips.org.pk/ abstract files/PDHS\%20Final $\% 20$ Report $\% 20$ as $\% 20$ of $\% 20$ Jan\%2022-2014.pdf.

3. Cleland J, Bernstein S, Ezeh A, Faundes A, Glasier A, Innis J. Family planning: the unfinished agenda. The Lancet. 2006; 368(9549):1810-27.

4. Rutstein SO. Further evidence of the effects of preceding birth intervals on neonatal infant and under-five-years mortality and nutritional status in developing countries: Evidence from the Demographic and Health Surveys. Macro International. $2008 ; 41$.

5. Kathpalia SK, Mustafa MS. Awareness about postpartum insertion of intrauterine device among antenatal cases. Med J Armed Forces Ind. 2015; 71(3):221-4.

6. Marston C. Report of a WHO Technical Consultation on Birth Spacing Geneva Switzerland 13-15 June 2005. Available at: http://www.who.int/maternalÿchildÿadolescent /documents/birthÿspacing.

7. Valliappan A, Dorairajan G, Chinnakali P. Postpartum intrauterine contraceptive device: Knowledge and factors affecting acceptance among pregnant/parturient women attending a large tertiary health center in Puducherry, India. Int J Adv Med Health Res. 2017; 4(2):69.

8. Katheit G, Agarwal J. Evaluation of post-placental intrauterine device (PPIUCD) in terms of awareness, acceptance, and expulsion in a tertiary care centre. Int J Reprod Contracept Obstet Gynecol. 2016; 2(4):539-43.

9. Verma A, Chawla I. A follow up study of postpartum intrauterine device insertion in a tertiary health care centre. Int J Reprod Contracept Obstet Gynecol. 2017; 6(7):2800-5.

10. Kaneshiro B, Aeby T. Long-term safety, efficacy, and patient acceptability of the intrauterine Copper T-380A contraceptive device. Int J Women's health. 2010; 2:211.

11. Byrd JE, Hyde JS, DeLamater JD, Plant EA. Sexuality during pregnancy and the year postpartum. J Fam Pract. 1998; 47(4):305-9.

12. Suri V. Post placental insertion of intrauterine contraceptive device. Indian J Med Res. 2012; 136(3):370.

13. Elahi N, Koukab H. Diagnosis and management of lost intrauterine contraceptive device. JPMA 2002; 52: 18-21.

14. Mustafa R, Qamar H, Nasreen K. Immediate Post-Placental Insertion versus Interval Insertion of Intrauterine Devices for Contraception. JBUMDC 2015; 5(2): 77-80.
15. Hooda R, Mann S, Nanda S, Gupta A, More H, Bhutani J. Immediate postpartum intrauterine contraceptive device insertions in caesarean and vaginal deliveries: a comparative study of follow-up outcomes. Int J Rep Med. 2016.

16. Goldstuck ND, Steyn PS. Insertion of intrauterine devices after cesarean section: a systematic review update. Int J Women's health. 2017; 9: 205-12.

17. Department of Economic and Social Affairs, United Nations Statistics Division, United Nations. Millennium Development Goals indicators. Available at: http://mdgs.un.org /unsd/ mdg/ Data.aspx

18. Jairaj S, Dayyala S. A cross sectional study on acceptability and safety of IUCD among postpartum mothers at tertiary care hospital, Telangana. J Clin Diagn Res 2016; 10:1-4.

19. Mohamed SA, Kamel MA, Shaaban OM, Salem HT. Acceptability for the use of postpartum intrauterine contraceptive devices: Assiut experience. Med Princ Pract $2003 ; 12: 170-5$.

20. United Nations Population information network (POPIN), UN Population division, Department of Economic and Social Affairs with support from UN Population Fund. Network Intrauterine devices. Fam Health Int. 1996; 16(2).

21. Shukla M, Sabuhi Qureshi C. Post-placental intrauterine device insertion-A five year experience at a tertiary care centre in north India. Indian J Med Res. 2012; 136(3):432.

22. Gupta G, Goyal R, Kadam VK, Sharma P. The Clinical Outcome of Post Placental Copper-T-380A Insertion with Long Placental Forceps (Kelly's Forceps) After Normal Vaginal Delivery and Cesarean Section. J of Obstet \& Gyne Ind. 2015; 65(6):386-8.

23. Mishra S. Evaluation of safety, efficacy, and expulsion of post-placental and intra-cesarean insertion of intrauterine contraceptive devices (PPIUCD). J of Obstet \& Gyne Ind. 2014; 64(5):337-43.

24. Araujo VB, Ortiz L, Smith J. Postpartum IUD in Paraguay. A case series of 3000 cases. Contraception. 2012;86(2):1734.

25. Kumar S, Sethi R, Balasubramaniam S, Charurat E, Lalchandani K, Semba R, Sood B. Women's experience with postpartum intrauterine contraceptive device use in India. Rep health. 2014;11(1):32.

26. Gupta $\mathrm{V}$ et al,. A Rare case of Perforation following PPIUCD insertion. J Obstet Gynaecol India. 2016;66(4):292-4.

27. Çelen P, Sucak A, Yýldýz Y, Danýpman N. Immediate postplacental insertion of an intrauterine contraceptive device during cesarean section. Contraception. 2011;84(3):240-3.

28. Ragab A, Hamed HO, Alsammani MA, Shalaby H, Nabeil H, Barakat R et al. Expulsion of Nova-T380, Multiload 375, and Copper-T380A contraceptive devices inserted during cesarean delivery. Int J Gynaecol Obstet. 2015;130(2):1748.

29. Ali R, Kausar S, Akram A. Post-placental Intrauterine Contraceptive Device at Cesarean Section. APMC 2015; 9(4):189-93. 